\title{
Intercomparison study of six HTDMAs: results and recommendations
}

\author{
J. Duplissy ${ }^{1}$, M. Gysel ${ }^{1}$, S. Sjogren ${ }^{1}$, N. Meyer ${ }^{2, *}$, N. Good ${ }^{3}$, L. Kammermann ${ }^{1}$, V. Michaud ${ }^{4}$, R. Weigel ${ }^{4}$, \\ S. Martins dos Santos ${ }^{5}$, C. Gruening ${ }^{5}$, P. Villani ${ }^{4}$, P. Laj $^{4}$, K. Sellegri ${ }^{4}$, A. Metzger ${ }^{1}$, G. B. McFiggans ${ }^{3}$, G. Wehrle ${ }^{1}$, \\ R. Richter ${ }^{1}$, J. Dommen ${ }^{1}$, Z. Ristovski ${ }^{2}$, U. Baltensperger ${ }^{1}$, and E. Weingartner ${ }^{1}$ \\ ${ }^{1}$ Laboratory of Atmospheric Chemistry, Paul Scherrer Institut, 5232, Villigen PSI, Switzerland \\ ${ }^{2}$ International Laboratory for Air Quality and Health, Queensland University of Technology, QLD 4000, Brisbane, Australia \\ ${ }^{3}$ Centre for Atmospheric Sciences, University of Manchester, M13 9PL, Manchester, UK \\ ${ }^{4}$ Laboratoire de Météorologie Physique, Blaise Pascal Univ., 63000, Clermont-Ferrand, France \\ ${ }^{5}$ Climate Change Unit, Joint Research Center, 21027, Ispra, Italy \\ *now at: Laboratory for Energy Analysis, Paul Scherrer Institut, 5232, Villigen PSI, Switzerland
}

Received: 22 August 2008 - Published in Atmos. Meas. Tech. Discuss.: 30 October 2008

Revised: 3 June 2009 - Accepted: 17 June 2009 - Published: 24 July 2009

\begin{abstract}
We report on an intercomparison of six different hygroscopicity tandem differential mobility analysers (HTDMAs). These HTDMAs are used worldwide in laboratory experiments and field campaigns to measure the water uptake of aerosol particles and have never been intercompared. After an investigation of the different design of the instruments with their advantages and inconveniencies, the methods for calibration, validation and data analysis are presented. Measurements of nebulised ammonium sulphate as well as of secondary organic aerosol generated from a smog chamber were performed. Agreement and discrepancies between the instruments and to the theory are discussed, and final recommendations for a standard instrument are given, as a benchmark for laboratory or field experiments to ensure a high quality of HTDMA data.
\end{abstract}

\section{Introduction}

Atmospheric aerosols are typically hygroscopic and absorb significant amounts of water at high relative humidity (RH). Hygroscopic growth with increasing RH influences the light scattering by particles, their potential to act as cloud condensation nuclei, and their chemical reactivity. The RH dependence of light scattering is one of the parameters needed to estimate the direct climate forcing by aerosol particles.

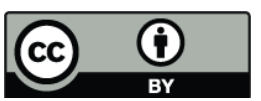

Correspondence to: E. Weingartner (ernest.weingartner@psi.ch)
Thus, the dry aerosol particle size distribution and their sizedependent hygroscopic growth factors must be known to model the humidity dependence of the light scattering of an aerosol. Efforts are currently undertaken to include the effects of hygroscopic growth of aerosol particles in global climate models (GCM) in order to better predict the scattering properties and size distribution of aerosols under varying humidity conditions (Randall et al., 2007). The two most widely used techniques enabling measurement of the change in the amount of water absorbed to an aerosols particle with varying $\mathrm{RH}$ are the single aerosol particle levitation technique using an electrodynamic balance (EDB; Tang and Munkelwitz, 1993) and the hygroscopicity tandem differential mobility analyser technique (HTDMA; Liu et al., 1978; Swietlicki et al., 2008). The EDB technique, which measures the properties of individual super-micrometer aerosol particles, is suitable for laboratory measurements. The HTDMA technique, which probes the hygroscopicity of all aerosol particles of a well-defined dry diameter at once, is suitable for field and laboratory measurements. HTDMA instruments cover the sub-micrometer diameter range, which contains the majority of the atmospheric aerosol particles.

All HTDMAs existing worldwide are custom built instruments and very few intercomparison studies between different instruments have been reported. This gap has been filled with this study as part of the EC project EUSAAR (European Supersites for Atmospheric Aerosol Research; http://www. eusaar.net/). Two intercomparison workshops have been conducted involving in total six different HTDMAs from five research groups with the aim to harmonise the design and the

Published by Copernicus Publications on behalf of the European Geosciences Union. 
quality assurance protocols of HTDMAs. This was done in order to ensure comparability of field measurements taken by different research groups. The overall objective of EUSAAR is the integration for air quality and climate studies of measurements of atmospheric aerosol properties performed in a distributed network of 20 high quality European groundbased stations.

The goals of these two instrument intercomparison workshops were threefold: first, careful calibration of the instruments and validation of performance and accuracy by measurement of different pure aerosols with well-known behaviour; second, identification of the reasons for discrepancies between the measurements from different instruments; third, instrument comparison using a complex organic aerosol with unknown properties.

Secondary organic aerosol (SOA) generated in a smog chamber was chosen for that purpose. SOA is of particular interest because more than $50 \%$ of organic aerosol is formed via oxidation and subsequent condensation of gaseous compounds (Hallquist et al. 2009). Characterisation of the hygroscopic properties of such SOA is a topic of current research.

In conclusion to this study, recommendations for HTDMA operation within EUSAAR are presented. The instruments shown in this study have been upgraded accordingly in order to ensure quality and comparability of field measurements performed by the different instruments at the EUSAAR supersites.

\section{Experimental section}

\subsection{HTDMA operation principle}

During operation of an HTDMA, a quasi-monodisperse size cut of aerosol particles with dry diameter $D_{0}$ at $\mathrm{RH} \leq 15 \%$ is selected from a polydisperse aerosol using a differential mobility analyser (DMA). Upon exiting the first DMA (DMA1) the aerosol is conditioned in a controlled humid environment before being passed into the second DMA (DMA2), which is held at a well defined RH. DMA2 is used to detect the resulting equilibrium aerosol particle diameter $D(\mathrm{RH})$, which is normally larger than $D_{0}$ due to water absorption. The hygroscopic diameter growth factor (GF) is defined as the measured mobility diameter ratio:

$\mathrm{GF}(\mathrm{RH})=\frac{D(\mathrm{RH})}{D_{0}}$

The sizing of the aerosol after humidification can be done in two alternative ways: Either by ramping the voltage (diameter) set point at DMA2 in discrete steps (commonly referred to as differential mobility particles sizer, DMPS) or by scanning the diameter range with a continuous exponential voltage ramp (commonly referred to as scanning mobility particle sizer, SMPS), while recording the aerosol particle number concentration with a concentration particle counter
(CPC). The former method is slightly slower, whereas the latter method may result in a smearing of the measurement signal, if too short scan times are used (Weingartner et al., 2002). The total time for a single scan is of the order of $5 \mathrm{~min}$, thus optimising the trade-off between maximising counting statistics and minimising the influence of variations of the aerosol concentration at the HTDMA inlet, which distort the recorded growth factor distribution. The measurement frequency can be increased considerably by constraining the scanned diameter range to a physically reasonable growth factor range for the aerosol being sampled and the $\mathrm{RH}$ set point.

\subsection{Design of instruments}

Six instruments, originating from five research groups from Australia, France, Great Britain, Italy and Switzerland participated in the two HTDMA intercomparison workshops conducted at the Paul Scherrer Institute (PSI), Switzerland, during summer 2006 and winter 2007. Technical specification and literature references for each HTDMA named HTDMA1 through HTDMA6) are given in Table 1. HTDMA1 was present during both campaigns whereas HTDMA2 and 3 were present only during the first and HTDMA4, 5 and 6 only during the second intercomparison.

Figure 1 shows the corresponding schematics illustrating the different humidification systems, inputs and process variables for RH regulation and the temperature stabilised regions. These are key factors that influence the accuracy and reproducibility of the measurements.

\subsubsection{Sheath air flow systems}

All HTDMAs were designed with recirculating sheath/excess air systems in the DMA. This has the advantage of maintaining a more similar gas phase composition in the sheath air compared to the sample and facilitates easier sheath air RH control. Vacuum pumps are commonly used to generate recirculating sheath/excess air flows and have proven to be a robust method (Biskos et al., 2006; Johnson et al., 2008; Weingartner et al., 2002). HTDMA2 through HTDMA6 applied the closed loop/vacuum pump set-up using a critical orifice or mass flow controller to control the sheath/excess air flow rate (see Table 1). Important considerations when choosing a pump are leak tightness, stability of the flow rate and an inert head space. The pistons in vacuum pumps generally operate at a frequency low enough to cause periodic flow oscillations. Rapid flow rate oscillations caused by the pump diaphragm can be dampened using a series of flowthrough volumes (Johnson et al., 2005) at the exit of the pump or by flow restrictions imposing a slight overpressure (Fletcher et al., 2007; Weingartner et al., 2002). In some setups, the overpressure tubes must be kept at a slightly higher temperature to avoid water condensation. Prior to the DMA temperature equilibration can be achieved 
Table 1. Technical description of the six HTDMAs.

\begin{tabular}{|c|c|c|c|c|c|c|}
\hline Specificities/HTDMA & HTDMA1 & HTDMA2 & HTDMA3 & HTDMA4 & HTDMA5 & HTDMA6 \\
\hline Reference paper & Duplissy et al. (2008) & Johnson et al. (2008) & $\begin{array}{l}\text { Cubison et al. (2005); Gysel } \\
\text { et al. (2007) }\end{array}$ & $\begin{array}{l}\text { Weingartner et al. } \\
\text { (2002); Gysel et al. } \\
(2002)\end{array}$ & $\begin{array}{l}\text { Van Dingenen } \\
\text { et al. (2005) }\end{array}$ & Villani et al. (2008 \\
\hline \multicolumn{7}{|l|}{ Humidification system } \\
\hline Water vapour source & $\begin{array}{l}\text { bubbling air through } \\
\text { liquid water }\end{array}$ & $\begin{array}{l}\text { diffusion humidifier } \\
\text { filled with water saturated } \\
\text { vermiculite }\end{array}$ & $\begin{array}{l}\text { bubbling air through } \\
\text { liquid water }\end{array}$ & $\begin{array}{l}\text { bubbling air through } \\
\text { liquid water }\end{array}$ & $\begin{array}{l}\text { heated liquid } \\
\text { water, separated by a }^{\mathrm{TM}} \text { tube } \\
\text { Nafion }\end{array}$ & $\begin{array}{l}\text { controlled injection } \\
\text { of liquid water on } \\
\text { heated resistance }\end{array}$ \\
\hline Humidity control & $\begin{array}{l}\text { PID controller \& } \\
\text { switching valves }\end{array}$ & $\begin{array}{l}\text { PID controller \& } \\
\text { switching valves }\end{array}$ & $\begin{array}{l}\text { Variable speed pumps mix- } \\
\text { ing dry and wet air }\end{array}$ & $\begin{array}{l}\text { PID controller \& } \\
\text { switching valves }\end{array}$ & $\begin{array}{l}\text { Temperature of the } \\
\text { heated liquid water }\end{array}$ & $\begin{array}{l}\text { Injection of correct } \\
\text { amount of water }\end{array}$ \\
\hline $\begin{array}{l}\text { Humidification of the } \\
\text { sample (Through what?) }\end{array}$ & Gore Tex & Nafion tube & Gore Tex & Gore Tex & Nafion tube & Nafion tube \\
\hline Humidification & sample flow only & $\begin{array}{l}\text { both sample flow } \\
\text { and sheath air }\end{array}$ & sample flow only & sample flow only & $\begin{array}{l}\text { Prehumidification, } \\
(\mathrm{RH}=50 \%) \text { of sample } \\
\text { flow, and sheath air }\end{array}$ & $\begin{array}{l}\text { both sample flow } \\
\text { and sheath air }\end{array}$ \\
\hline $\begin{array}{l}\text { Feedback control for } \mathrm{RH} \text { from } \\
\text { DMA2 }\end{array}$ & No & Yes & No & Yes & No & Yes \\
\hline $\begin{array}{l}\text { Residence time of the sample } \\
\text { at the correct RH before enter- } \\
\text { ing the DMA2 [s] }\end{array}$ & 15 & 4 & 30 & 8 & $\begin{array}{l}0 \text {, prehumidification } \\
\text { ( } \mathrm{RH}=50 \% \text { ) of sample } \\
\text { flow, and sheath air }\end{array}$ & 2 \\
\hline $\begin{array}{l}\text { Prehumidificator option } \\
\text { or not }\end{array}$ & No & No & Yes & No & Yes $(\mathrm{RH}=50 \%)$ & Yes \\
\hline \multicolumn{7}{|l|}{ Humidification Performance } \\
\hline $\begin{array}{l}\text { Time needed to go from } \\
90 \% \text { to dry and back to } \\
90 \% \mathrm{RH}[\mathrm{h}]\end{array}$ & 10 & 0.5 & 1 & 5 & 1 & 0.5 \\
\hline $\begin{array}{l}\text { Maximun RH with good } \\
\text { stability }\end{array}$ & 95 & 95 & 90 & 95 & 90 & 90 \\
\hline $\begin{array}{l}\text { RH stability under stable con- } \\
\text { dition }[\%] \pm \text { Standard devia- } \\
\text { tion }\end{array}$ & $95 \pm 0.25$ & $95 \pm 0.07$ & $73 \pm 1$ & $90 \pm 0.3$ & $87 \pm 0.6$ & $85 \pm 0.2$ \\
\hline $\begin{array}{l}\text { Time used to perform RH sta- } \\
\text { bility }[\mathrm{h}]\end{array}$ & 10 & 4 & 12 & 5.5 & 6 & 9.5 \\
\hline $\begin{array}{l}\text { Capacity to keep stable } \\
\text { RH if drop of the lab } \\
\text { temperature }\end{array}$ & Yes & Yes & Not tested & No & No & Yes \\
\hline Automatic humidogram & Yes & Yes & Yes & Yes & No & No \\
\hline \multicolumn{7}{|l|}{ RH sensor } \\
\hline Type of sensor & $\begin{array}{l}\text { Dew Point mirror } \\
\text { (Edge) }\end{array}$ & $\begin{array}{l}\text { Dew Point mirror } \\
\text { (Optidew from Michell In- } \\
\text { struments) }\end{array}$ & $\begin{array}{l}\text { Dew Point mirror } \\
\text { (GE) }\end{array}$ & $\begin{array}{l}\text { Dew Point mirror } \\
\text { (Edge) }\end{array}$ & $\begin{array}{l}\text { Capacitive sensor } \\
\text { (Humicap Sensors } \\
\text { from Vaisala) }\end{array}$ & $\begin{array}{l}4 \text { Capacitive } \\
\text { sensors }\end{array}$ \\
\hline Accuracy at $90 \% \mathrm{RH}[\%]$ & \pm 1.2 & \pm 1.2 & \pm 1.2 & \pm 1.2 & \pm 2 & \pm 2 \\
\hline Precision of the sensor & \pm 0.1 & \pm 0.1 & \pm 0.1 & \pm 0.1 & \pm 1.7 & \pm 1.7 \\
\hline $\begin{array}{l}\text { Position of the probe } \\
\text { in the system }\end{array}$ & Excess air & Excess air & Excess air & Excess air & Excess air & Excess air \\
\hline \multicolumn{7}{|l|}{ Flows system } \\
\hline Closed or open loop & Closed & Closed & Closed & Closed & Closed & Closed \\
\hline Pump or blower & Blower & Pump & Pump & Pump & Pump & Pump \\
\hline Regulation of the flows & PID & MFC & Critical Orifice & Critical Orifice & Critical Orifice & MFC \\
\hline Flow DMA1 [1/min] & $6 \pm 0.01$ & $10 \pm 0.05$ & $5.5 \pm 0.01$ & $3 \pm 0.01$ & $8.6 \pm 0.1$ & $10 \pm 0.05$ \\
\hline $\begin{array}{l}\text { Flow aerosol DMA1 } \\
{[1 / \mathrm{min}]}\end{array}$ & $0.6 \pm 0.05$ & $2 \pm 0.1$ & $0.55 \pm 0.05$ & $0.3 \pm 0.05$ & $0.97 \pm 0.05$ & $2 \pm 0.1$ \\
\hline Flow DMA2 $[1 / \mathrm{min}]$ & $3 \pm 0.01$ & $5 \pm 0.051$ & $5.5 \pm 0.01$ & $3 \pm 0.01$ & $8.7 \pm 0.1$ & $5 \pm 0.05$ \\
\hline $\begin{array}{l}\text { Flow aerosol DMA2 } \\
{[1 / \mathrm{min}]}\end{array}$ & $0.3 \pm 0.05$ & $1 \pm 0.05$ & $0.55 \pm 0.05$ & $0.3 \pm 0.05$ & $0.97 \pm 0.05$ & $1 \pm 0.05$ \\
\hline \multicolumn{7}{|l|}{ Temperature control system } \\
\hline DMA1 & Box $T$ regulated & none & none & $\begin{array}{l}\text { Water bath not } \\
T \text { regulated }\end{array}$ & none & none \\
\hline Humidification part & $T$ regulated & none & none & none & none & $T$ regulated \\
\hline DMA2 & Box $T$ regulated & $\begin{array}{l}\text { thermally isolated } \\
\text { environment }\end{array}$ & $\begin{array}{l}\text { Water bath not } T \\
\text { regulated }\end{array}$ & $\begin{array}{l}\text { Water bath not } T \\
\text { regulated }\end{array}$ & $\begin{array}{l}\text { thermally isolated } \\
\text { environment }\end{array}$ & Box $T$ regulated \\
\hline \multicolumn{7}{|c|}{ Temperature stability during SOA measurement } \\
\hline DMA1 $\left(T \pm d T^{\circ} \mathrm{C}\right)$ & $25+/-0.1$ & Lab T. & Lab T. & Lab T. & Lab T. & Lab T. \\
\hline $\begin{array}{l}\text { Humidification part } \\
\left(T \pm d T^{\circ} \mathrm{C}\right)\end{array}$ & $25+/-0.1$ & Lab T. & Lab T. & Lab T. & Lab T. & Lab T. \\
\hline $\begin{array}{l}\text { DMA2 } \\
\left(T \pm d T^{\circ} \mathrm{C}\right)\end{array}$ & $20+/-0.1$ & Lab T. & Lab T. & Lab T. & Lab T. & $19.5+/-0.3$ \\
\hline \multicolumn{7}{|l|}{ HTDMA performance } \\
\hline Size measured with & 1st Worshop: & $101 \pm 0.2$ & $101.8 \pm 0.3$ & $104.3 \pm 1$ & $106.9 \pm 3.3$ & $97 \pm 1$ \\
\hline DMA1 set to select & $100 \pm 0.05$ & & & & & \\
\hline $\begin{array}{l}100 \mathrm{~nm} \text { diameter aerosol parti- } \\
\text { cles and standard } \\
\text { deviation }\end{array}$ & $\begin{array}{l}\text { 2nd Workshop: } \\
98.5 \pm 0.05\end{array}$ & & & & & \\
\hline $\begin{array}{l}\text { Time required for } D_{0} \\
\text { stability [h] }\end{array}$ & 48 and 24 & 9.5 & 22 & 28 & 3 & 2 \\
\hline $\begin{array}{l}\text { Measurable size } \\
\text { range DMA2 [nm] }\end{array}$ & 30 to 600 & $\sim 15$ to 350 & $\sim 20$ to 800 & 30 to 600 & 30 to 350 & $\sim 15$ to 350 \\
\hline Sizing mode & scanning & scanning & stepping & scanning & stepping & stepping \\
\hline $\begin{array}{l}\text { Second CPC for total } \\
\text { number variation exiting } \\
\text { DMA1 }\end{array}$ & No & No & No & No & No & Yes \\
\hline
\end{tabular}




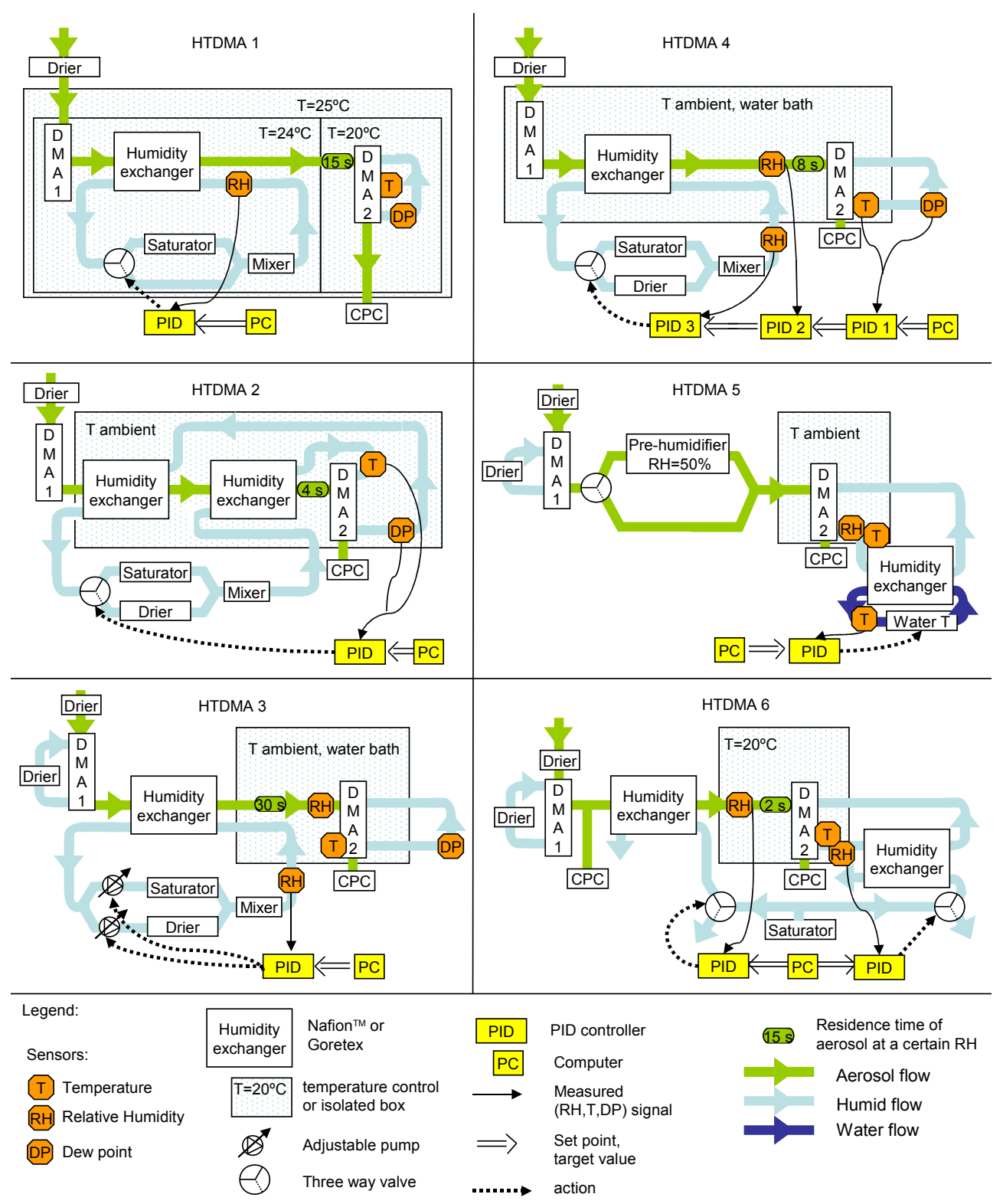

Fig. 1. Schematics of all HTDMAs illustrating the humidity production principles, PID feedbacks for RH regulation, and temperature stabilised parts.

by directing the sheath air through an in-line heat exchanger. HTDMA1 worked also with a closed loop sheath/excess air set-up, whereas PID-controlled blowers instead of vacuum pumps were used to generate the air flow. Despite the fact that precise regulation of the blower power and leak tightness are critical (Paulsen et al., 2006), this set-up has the advantage that the recirculating air stream is hardly heated nor compressed.

\subsubsection{Temperature stability}

Growth factor measurements in a HTDMA at a well defined $\mathrm{RH}$ are only meaningful if temperature gradients in DMA2 are $\leq 0.1 \mathrm{~K}$ because a temperature change of $\pm 0.1 \mathrm{~K}$ results in an RH change of $\pm 0.6 \%$ at an $\mathrm{RH}$ of $90 \%$. The first HTDMA systems used passive temperature control methods (McMurry and Stolzenburg, 1989) ideally keeping their systems in air-conditioned rooms or insulating them from their surroundings (Virkkula et al., 1999), before active temperature control was introduced (Brechtel et al., 2000; Prenni et al., 2001). Present HTDMA instruments use water baths 
(Cubison et al., 2005; Hennig et al., 2005; Weingartner et al., 2002), temperature controlled cabinet (Cocker III et al., 2001; Duplissy et al., 2008; Prenni et al., 2001; Villani et al., 2008) or passive, insulated regions (Johnson et al., 2008; Virkkula et al., 1999). HTDMA1 and 6 of this study had at least DMA2 operated in a temperature controlled cabinet; HTDMA3 and 4 had at least DMA2 submersed in a water bath; the DMA2 of HTDMA2 and 5 were placed in a thermally isolated environment (see Fig. 1 and Table 1).

\subsubsection{Humidifier design and $\mathrm{RH}$ regulation}

A requirement of aerosol humidifiers is that the aerosol particles are humidified in a controlled and stable manner. The humidification system must generate water vapour, transfer the water vapour into the aerosol sample and/or sheath air flows and regulate the resulting RH. Exclusive humidification of the aerosol sample flow is only possible for HTDMAs using a closed loop sheath air set-up for DMA2, where the $\mathrm{RH}$ of the sheath air will follow the RH of the incoming sample flow with a certain delay. Additional humidification of the sheath air flow is required for HTDMAs with an open sheath/excess air set-up and it can also be applied to significantly shorten the response time to RH set point changes for HTDMAs using a closed loop set-up. Furthermore it is easier to control sheath and excess air in a closed loop setup.

The generation of water vapour can be achieved by passing air over a surface of liquid water, possibly separated by a membrane such as Goretex ${ }^{\mathrm{TM}}$ or Nafion ${ }^{\mathrm{TM}}$, by bubbling air directly through water, or by using a water vapour saturated vermiculite. From the vapour source, the transfer of the water vapour into the sample or sheath flow is normally done with a laminar flow humidity exchanger or through a membrane such as Goretex ${ }^{\mathrm{TM}}$ or Nafion ${ }^{\mathrm{TM}}$. A source of dry air is applied by most instruments for RH regulation or for active drying of the sample flow. Connecting a vacuum pump to a Nafion ${ }^{\mathrm{TM}}$ dryer is a technique to generate dry air, which does not need regular maintenance nor any regeneration. Alternatively, Nafion ${ }^{\text {TM }}$ dryers can be used, which require an extra source of dry air or an additional vacuum pump.

Regulation of the humidity has been achieved by mixing humid and dry air in variable proportions (Biskos et al., 2006; Cubison et al., 2005; Johnson et al., 2008; McMurry and Stolzenburg, 1989; Weingartner et al., 2002), by temperature control of the liquid water, which acts as the vapour source (Virkkula et al., 1999), or by a combination of these two methods (Cruz and Pandis, 2000).

HTDMA1, 2, 3 and 4 can perform a scanning of the RH in DMA2 automatically, while HTDMA5 and 6 require manual operation for RH set point changes. The latter makes it more difficult to achieve sufficient RH resolution in the hydration curve needed e.g. for a precise characterization of the deliquescence transition (see Sect. 3.2). The humidification set- up of the instruments involved in this intercomparison workshop are summarised in Table 1 and Fig. 1.

\subsubsection{Residence time of the aerosol at high RH}

A residence time sufficiently long to reach the equilibrium growth factor at an RH virtually equal to the RH in DMA2 is required such that no significant growth occurs during sizing in DMA2. Various papers have discussed whether organic/inorganic aerosol mixtures show mass transfer limitations of water uptake (contrary to pure inorganic salts which equilibrate within timescales of $<1 \mathrm{~s}$ ). Kerminen et al. (1997) considered the gas-phase transfer to particles before cloud activation, and calculated equilibration times $<1 \mathrm{~s}$. However, Chuang et al. (2003) found during a field study in Mexico City that $0-2 \%$ of the aerosol particles exhibited growth times larger than 2-3s, which was explained by a low mass accommodation coefficient. Sjogren et al. (2007) and Chan and Chan (2005) showed in laboratory experiments that certain organic substances mixed with inorganic salts can have equilibration times larger than $40 \mathrm{~s}$. Therefore HTDMAs should be equipped with a residence chamber held at an RH virtually equal to the RH in DMA2, where the aerosol particles have sufficient time for equilibration before sizing in DMA2. On the other hand volatile aerosol particles may suffer from evaporation artefacts inside the HTDMA if the residence time exceeds a few tens of seconds. Gysel et al. (2007) and Mikhailov et al. (2004) demonstrated that this artefact can occur for ammonium nitrate particles. It can be expected that also other compounds (e.g. semivolatile organics) may show this effect (Koehler et al. 2006). Evaporation artefacts, which will most likely lead to an underestimation of the GF, can be minimised by shortening the residence time or by decreasing the temperature. Clearly further studies are needed to identify the optimum residence time. Residence times of the different HTDMA instruments used in this study are given in Table 1.

In addition to the residence time effects, Biskos et al. (2006) observed that significant differences between the $\mathrm{RH}$ of sample and sheath flow $(\geq 3 \% \mathrm{RH})$, can lead to erroneous results for inorganic salts. Therefore it is recommended to keep the RH difference between aerosol sample flow and sheath air flows as small as possible, ideally $\leq \pm 2 \%$. This is impossible in systems which do not control the humidity in the sample flow, but only in the DMA2 sheath flow such as HTDMA5. This system has only an uncontrolled prehumidifier in the aerosol sample flow while operating above $60 \% \mathrm{RH}$. It is shown below (see Sect. 4.1.4 and 4.2) that this can cause measurement artefacts. The humidification system of HTDMA2, with a single humid purge flow for the humidification of sheath air and aerosol sample flows, keeps the RH differences to a minimum (Johnson et al., 2008). Data presented in this paper are only reported if the RH difference was $\leq 2 \%$ (except for HTDMA5 which can not fulfil this criterion due to its design). 


\subsubsection{Measurement of the relevant $\mathrm{RH}$}

The RH in DMA2 determines the GF which is measured by a HTDMA given that the residence time at this RH is sufficiently long to reach equilibrium. Measurement of the RH is normally the major source of uncertainty in HTDMA GF measurements. Previous studies have reported GF data with an RH uncertainty of up to $\pm 4 \%$ RH (Prenni et al., 2007). As an example the theoretical GF of pure ammonium sulphate at an RH of 86 and $94 \%$ is 1.61 and 2.01, respectively, thus illustrating the large uncertainty of GF imposed through the uncertainty of RH. HTDMA5 and 6 used capacitive RH sensors (Humicap Sensors from Vaisala) for direct RH and temperature measurements, which are less expensive but also less accurate than dew point hygrometers. The HTDMA1 to 4 measured the RH indirectly through accurate temperature and dew point measurements using a PT100 resistance temperature detector (RTD) and a dew point mirror (DPM), respectively. The temperature probes were placed in the water bath (HTDMA4), attached to the outer wall of DMA2 (HTDMA1), inside DMA2 (HTDMA3), or in the excess air flow (HTDMA2). For a typical dew-point hygrometer, the accuracy of the temperature and dew point temperature measurement is $\pm 0.15^{\circ} \mathrm{C}$, translating into a $\mathrm{RH}$ accuracy of $\pm 1.2 \%$ at $90 \% \mathrm{RH}$ and $T=20^{\circ} \mathrm{C}$. In comparison, capacitive sensors have generally an accuracy of $\pm 1.5 \%$ when measuring within their specified $\mathrm{RH}$ range. A further advantage of dew point sensors is that only the temperature has to be measured in the DMA2 while the dew point can be monitored at some distance of DMA2, as long as the partial pressure of the water vapour is not altered by e.g. pressure drop in the transfer line. A disadvantage of using a capacitive sensor is that the RH measurement has to be done in the sizing column of DMA2. Otherwise additional temperature probes are required to correct the measured $\mathrm{RH}$ for potential temperature differences. Most HTDMAs instruments can reliably measure at $\mathrm{RH} \leq 90 \%$, whereas measuring at $\mathrm{RH} \geq 95 \%$ is a challenge. Reaching 95\% RH is possible with optimised humidifiers (e.g. HTDMA2) or by cooling the sample flow after humidification (e.g. HTDMA1). Furthermore, the risk of condensation increases and possible consequences are high voltage arcs in DMA2 potentially damaging the instrument.

\subsection{Aerosol generation}

The HTDMA intercomparison was done with inorganic salts with known hygroscopic growth and with secondary organic aerosols produced by photochemical oxidation of gaseous precursors. The latter was used as a proxy for ambient secondary organic aerosol.

\subsubsection{Nebulisation of inorganic salts}

Artificial aerosol particles were generated by nebulisation of a $\sim 0.05 \mathrm{~g} / \mathrm{l}$ salt solution $\left(\left(\mathrm{NH}_{4}\right)_{2} \mathrm{SO}_{4}\right.$, purity $>99.5 \%$, Fluka;
$\mathrm{NaCl},>99.5 \%$, Merck; $\mathrm{NaNO}_{3},>99 \%$, Merck) in MilliQ water. The atomizer (TSI type 3076) was operated with clean air from a pure air generator (AADCO 737-series 15 A). The solution droplets were dried in a custom-built diffusion dryer with a residence time of $\sim 60 \mathrm{~s}$ prior distribution to all HTDMAs. All HTDMAs were supplied with aerosols from the same nebuliser in order to exclude potential discrepancies between instruments caused by differences in the samples.

\subsubsection{Secondary aerosol formation in a smog chamber}

Photo-oxidation experiments were carried out in a $27-\mathrm{m}^{3}$ Teflon chamber (Paulsen et al., 2005) at $20^{\circ} \mathrm{C}$ and $50 \% \mathrm{RH}$ and with $10( \pm 2)$ ppb of $\mathrm{NO}_{2} . \alpha$-Pinene (Aldrich, 98\%) was evaporated in a heated glass sampling bulb and flushed into the humidified chamber with pure air to generate a mixing ratio of $20( \pm 2) \mathrm{ppb}$. Rather low, atmospherically relevant precursor concentrations were chosen because it had been shown that high precursor concentrations reduce the hygroscopicity of photo-oxidized SOA due to gas-to-particle partitioning effects of the aerosol (Duplissy et al., 2008). Four xenon arc lamps ( $4 \mathrm{~kW}$ each) were used to simulate the solar light spectrum and initiate the photochemical reaction. Before turning on the lights the mixture was allowed to equilibrate within the chamber for approximately $30 \mathrm{~min}$. Nucleation of SOA particles was observed one hour after the lights were switched on, followed by condensational growth to a final diameter after $\sim 8 \mathrm{~h}$ of photo-oxidation. The aerosol particle number size distribution was measured using a TSI 3936 long column SMPS. The dry diameter selected by the HTDMAs was chosen to follow the current modal size of the SOA particle distribution, in order to make sure that the dominant fraction (at least $80 \%$ ) of selected aerosol particles carried a single charge.

\section{Calibration, validation and data analysis}

\subsection{Calibration}

The aerosol particle sizing by the DMA as well as the RH measurement can be checked and calibrated independently. Sizing is crucially dependent on correct flow rates and high voltage (HV) applied to the DMA. Therefore, all flows in the system, the analogue output for controlling the HV supply as well as the HV amplification factor must be calibrated. The performance of the DMA can be tested with certified particles of known size such as polystyrene latex (PSL) spheres, though this is difficult for diameter $D<100 \mathrm{~nm}$. Stable sizing by DMA1 and DMA2 in addition to exact knowledge of possible small sizing offsets is a prerequisite for accurate HTDMA measurements. Both can be tested by a dry offset calibration measurement using a non-volatile aerosol, where the humidification is simply switched off. Eventually DMA2 will stabilize at the same RH as DMA1 and hence the true GF of aerosol particles passing the HTDMA should be unity. 
The corresponding measured GF reveals the offset of the two DMAs. Correction of this offset in all measurement data is done by using the actual measured $D_{0}$ as a reference diameter for the calculated growth factors as proposed by Gysel et al. (2009). The temporal variability of the actual measured $D_{0}$ indicates the sizing stability of the HTDMA. Additionally, the final RH in DMA2 shows whether the RH in DMA1 is sufficiently low, when operated in dry mode.

The temperature and dew point temperature probes of a DPM can be independently calibrated. A common way to calibrate capacitive RH sensors or to validate DPM measurements is to expose them to the equilibrium $\mathrm{RH}$ above a saturated salt solution at a range of relevant temperatures. Equilibrium RH values for various saturated salt solutions can be found in literature (e.g. Tang and Munkelwitz, 1993). A calibration curve can be applied to correct the RH measurement of the capacitive sensors. Indirect RH calibration of RH sensors through measurement of the GF of pure salts is not recommended because the measured GFs can be biased by further effects such as non spherical particle shape (shape factor), restructuring, impurities, RH gradients in the DMA2 and inaccurate flow in DMA2. For dew point sensors, it is recommended to perform also a saturation test. The measured dew points can periodically be checked by feeding air saturated with water vapour into the dew point sensors at a well defined temperature (the same temperature as in the DMA2) and by measuring the resulting dew point and DMA2 temperature (Duplissy et al., 2008; Weingartner et al., 2002). This allows an internal calibration of the dew point sensors by adjusting the measured dew point temperatures to the measured DMA2 temperature. Care has to be taken that no water is lost by condensation in the transfer lines.

\subsection{Validation of HTDMA accuracy}

Periodic validation of accuracy and performance of a HTDMA should be tested with measurements of pure test substances with known hygroscopic properties such as ammonium sulphate.

The equilibrium size of inorganic aerosol particles in humid air often shows a hysteresis depending on their RH history (Seinfeld and Pandis, 2006). A crystalline particle exposed to increasing RH does not significantly change its size until the deliquescence relative humidity (DRH) is reached and a solution droplet is formed. At RH $>$ DRH the particle is always present as a solution droplet. Once in the liquid phase, the particle can exist in a meta-stable equilibrium state as a supersaturated solution droplet at a $\mathrm{RH}<\mathrm{DRH}$. Recrystallisation occurs at the efflorescence relative humidity (ERH) which is given by the supersaturation at which crystallization takes place. Hysteresis effects are very distinct for some inorganic salts such as sodium chloride or ammonium sulphate. Due to insoluble impurities, the crystallisation can occur at higher RH than the ERH. The DRH, ERH, and RH history of an atmospheric particle determines whether it is present as a solid or a liquid particle (Rood et al., 1999; Colberg et al., 2003; Wang et al., 2008), which is an important factor for many atmospheric impacts. Accurate measurement of DRH and ERH is hence an important specification of HTDMA instruments.

A standard online method to verify the accuracy of the measured $\mathrm{RH}$ is to measure the deliquescence point of pure salts (e.g. $\left(\mathrm{NH}_{4}\right)_{2} \mathrm{SO}_{4}$ and $\mathrm{NaCl}$ ). However, accurate determination of the deliquescence transition may be difficult or even impossible depending on the HTDMA set-up (see Sect. 2.2.3). Therefore, it is recommended to measure complete humidograms of ammonium sulphate including a full hydration curve with the deliquescence transition. A validation at a single RH is only a weak test because possible compensating effects from DMA performance, shape factors, restructuration, RH bias or impurities cannot always be excluded. The measurement of a full hydration curve helps to distinguish between sizing or RH measurement errors resulting in vertically or horizontally biased data points, respectively.

\subsection{Standard data analysis}

A first step of the data analysis is the determination of the actual measured $D_{0}$ as opposed to the nominal $D_{0}$ in order to account for small sizing offsets between the two DMAs as discussed in Sect. 3.1. The next step involves the inversion of the raw data with an appropriate algorithm (Swietlicki et al., 2008). We applied the TDMA inversion approach (TDMAinv) developed by Gysel et al. (2009). This algorithm uses a full TDMA kernel function and approximates the inverted growth factor probability density function (GF-PDF) as a piecewise linear function. The inversion routines are largely automated and the TDMAinv toolkit is available on the web (http://people.web.psi.ch/gysel/). Alternative inversion approaches are e.g. the TDMAfit algorithm introduced by Stolzenburg and McMurry (1988), which approximates the GF-PDF as a superposition of multiple Gaussians.

During measurements the RH in DMA2 varied around the target value. This caused concurrent variability of measured GFs. An empirical equation has been applied to recalculate measured GFs to their corresponding value at the target RH, thus minimizing this unwanted variability. Only measurements made at $\mathrm{RH}$ within a band of $\pm 2 \%$ around the target RH were considered and recalculated according to the approach described in Gysel et al. (2009). Recalculation of measurements to the nominal target RH is generally recommended in order to improve comparability of results from different studies.

\subsection{Interference of doubly charged aerosol particles}

A DMA selects aerosol particles by their electrical mobility which depends on their physical diameter and elementary charge. Therefore, aerosol particles selected by DMA1 

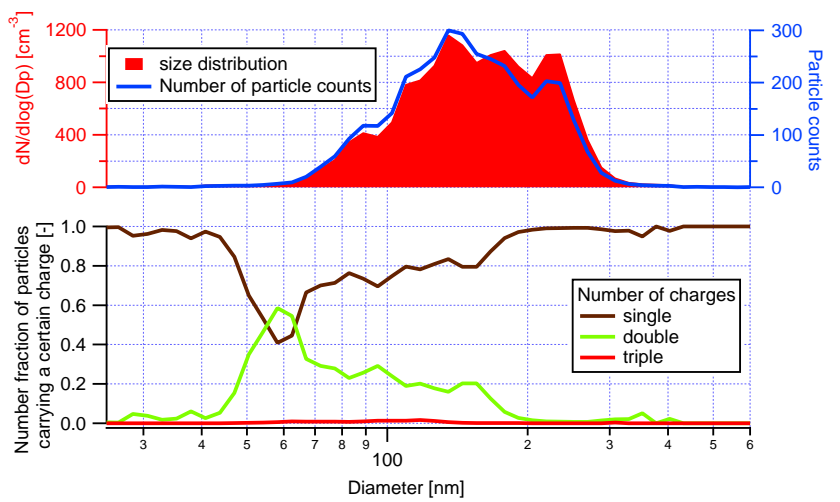

Fig. 2. This figure shows an example of ambient aerosol number size distribution (red shadings). The blue line indicates the raw counts recorded by the CPC as a function of electrical mobility diameter set at the DMA. The bottom panels show the proportion of aerosol particles carrying 1, 2, or 3 charges. In the example, the singly charged aerosol particles dominate $(\approx 80 \%)$ at set diameters bigger than $105 \mathrm{~nm}$ and an accurate HTDMA analysis is possible. Between diameter of $D_{0} \approx 60 \mathrm{~nm}$ and $D_{0} \approx 105 \mathrm{~nm}$ the selected physical diameter is not well defined because $\sim 40 \%$ of the aerosol particles are doubly charged, and data analysis is hampered. At $D_{0} \approx 60 \mathrm{~nm}$ doubly charged particles dominate $(\approx 60 \%)$.

of a HTDMA can have different physical diameters if they carry a different number of charges, with the following consequences (Gysel et al., 2009): First, the physical diameter of the selected dry aerosol particles may not be well defined, e.g. if the number fraction of singly and doubly charged aerosol particles is comparable. Second, converting measured electrical mobility growth factors into physical diameter growth factors depends on the number of charges on a particle. Assuming a single charge for multiply charged particles results in an underestimation of the physical diameter growth factor due to the nonlinearity of the Cunningham slip correction. The relative number fractions of singly, doubly or triply charged aerosol particles behind DMA1 depend on the shape of the polydisperse number size distribution of the dry aerosol particles entering the HTDMA.

For illustration, Fig. 2 shows an example of a number size distribution, as observed during field measurements, along with the calculated size dependent number fractions of singly, doubly and triply charged aerosol particles after the preclassification in DMA1. Often the singly charged aerosol particles dominate $(>80 \%)$ and the HTDMA data analysis is straight forward and not biased by the multiply charged aerosol particles. Under certain conditions the number fraction of multiply charged aerosol particles can be significant, e.g. at $D_{0} \approx 60 \mathrm{~nm}$ in Fig. 2 . In such cases the HTDMA signal is a superposition of contributions from different dry sizes, and hence an accurate retrieval of the growth information is impossible. Therefore HTDMA measurements must always be accompanied by number size distribution measure-

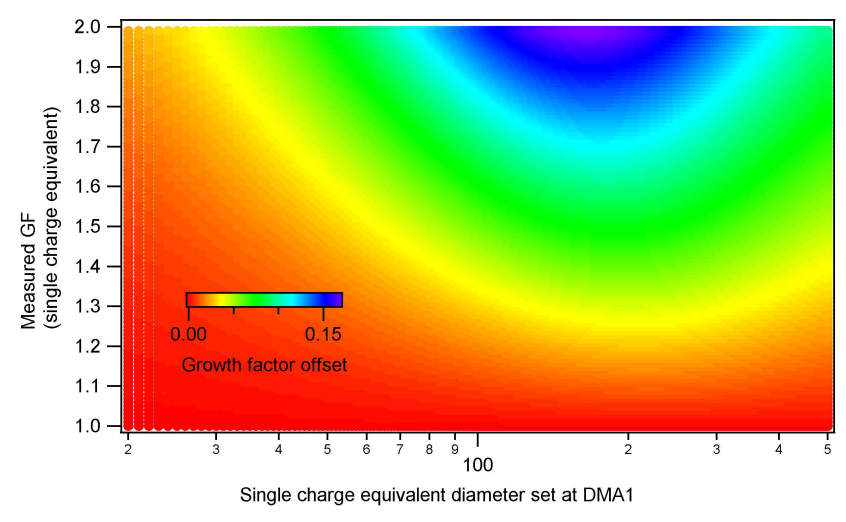

Fig. 3. Growth factor offset due to doubly charged aerosol particles. This figure shows a two-dimensional plot of the GF offset for doubly charged aerosol particles as a function of the diameter set at DMA1 and the single charge equivalent GF measured, defined as $\mathrm{GF}_{\text {true }}=\mathrm{GF}_{\text {measured }}+\mathrm{GF}_{\text {offset }}$.

ments and subsequent removal of those HTDMA data points, where the number fraction of singly charged aerosol particles dropped below a critical limit ( $\sim 80 \%)$. This applies for field measurements but is also important for measurements of laboratory generated particles: Nebulised aerosol particles are often relatively large (modal dry diameter $>100 \mathrm{~nm}$ ) and the HTDMA measurement of $\mathrm{D}<100 \mathrm{~nm}$ can be significantly biased by multiply charged aerosol particles.

Accurate data analysis is also possible if multiply charged aerosol particles dominate after size selection with a number fraction of more than $\sim 80 \%$ of doubly (or triply) charged aerosol particles. In such cases the HTDMA kernel function for two (or three) charges must be used for the inversion of the raw measurement distribution functions (Gysel et al., 2009). Alternatively the raw data can first be analysed as if all aerosol particles were singly charged, followed by correction of the obtained growth factors with a size and GF dependent offset as shown in Fig. 3. The technique of setting the DMA1 to a voltage, where predominantly doubly (or triply) charged aerosol particles were selected, has been used in a recent smog chamber study to extend the measurement range of HTDMA to larger diameters $\left(D_{0}=250-575 \mathrm{~nm}\right)$ (Duplissy et al., 2008).

\section{Results and discussion}

Here we first present several experiments conducted with pure ammonium sulphate which aim to validate the accuracy and performance of HTDMA1 through 6 against theory. A second series of experiments with SOA provides an intercomparison of the HTDMAs with a complex organic sample, where the actual behaviour is not known. This is followed by a discussion of discrepancies found between the measured GFs and theory as well as between the instruments. 


\subsection{Validation experiments with pure ammonium sul- phate}

\subsubsection{Sizing stability}

Dry ammonium sulphate particles were used to validate the stability of the diameter measurement. For this purpose the humidification of the HTDMA was switched off and the difference of the measured GF from unity revealed the sizing offset of the two DMAs (see above). The temporal variability of the actual measured $D_{0}$ indicates the sizing stability of the HTDMA. All instruments in this study were fairly stable with a temporal variability of $D_{0}$ of less than $\pm 1 \%$ (see Table 1). High reproducibility of the sizing is a key factor for accurate growth factor determination. Accurate size selection by DMA1 is less important. If DMA1 was to have a sizing offset of $+5 \%$, then the instrument would measure the properties of particles with a dry size of e.g. $105 \mathrm{~nm}$ instead of $100 \mathrm{~nm}$. This causes only minimal errors unless the aerosol composition is extremely size dependent. Nevertheless, correct size selection by DMA1 should be tested with certified PSL spheres.

\subsubsection{RH stability under constant laboratory tempera- ture conditions}

Here we show that the ability of a HTDMA to maintain constant RH is primarily determined by its humidification control and feedback system and how the critical parts are shielded against external temperature variations. All HTDMAs were able to hold the variability of the RH measured in DMA2 within $\pm 2 \%$ of the target RH (Table 1). HTDMA2, 4, and 6 are able to maintain a relatively constant RH in DMA2 (within $\pm 0.4 \% \mathrm{RH}$ ) because they use a PID controlled feedback from the RH measured in DMA2 to the humidifier load. HTDMA3 and 5 which do not have any RH feedback from DMA2 were less stable with a standard deviation higher than $\pm 0.6 \% \mathrm{RH}$ to the target value. HTDMA1, completely enclosed in a temperature controlled housing, achieved high stability with a standard deviation of $\pm 0.25 \% \mathrm{RH}$ even without a PID controlled feedback.

\subsubsection{RH stability under variable laboratory tempera- ture conditions}

Room temperature is often subject to considerable variations, particularly during field campaigns with basic facilities influenced by e.g. warming solar radiation or opening of windows and doors. The HTDMAs should still be able to acquire accurate GF measurements and whenever possible precisely at the set point RH. Tests with simulated room temperature drops were performed to reveal the robustness of the individual systems against such perturbations. Each system was first measuring the GF of a test compound at a stable laboratory temperature of $24^{\circ} \mathrm{C}$ and at a constant $\mathrm{RH}(90,85$ or $40 \%$, depending on the instrument/experiment). Then all doors and windows were opened leading to a sudden temperature drop down to $\sim 14^{\circ} \mathrm{C}$. This test has been done with ammonium sulphate aerosol for HTDMA1 and 4-6 during the second campaign and with citric acid for HTDMA2 and 3 during the first campaign. RH variations in DMA2 are undesirable though acceptable if they remain within $\pm 2 \% \mathrm{RH}$. However, this is only true if the RH measurement remains accurate despite the room temperature variations. The $\mathrm{RH}$ stability (right ordinate) of the HTDMAs during the above temperature drop test as well as the corresponding relative accuracy of the measured GFs (right ordinate) are illustrated in Fig. 4. The relative GF bias, $\mathrm{GF}_{\text {bias }}$, is defined as:

$\mathrm{GF}_{\text {bias }}=\frac{\mathrm{GF}_{\text {measured }}-\mathrm{GF}_{\text {theory }}\left(\mathrm{RH}_{\text {measured }}\right)}{\mathrm{GF}_{\text {theory }}\left(\mathrm{RH}_{\text {measured }}\right)}$

where $\mathrm{GF}_{\text {measured }}$ is the measured $\mathrm{GF}$ and $\mathrm{GF}_{\text {theory }}$ is the theoretical GF of the sample at measured $\mathrm{RH}, \mathrm{RH}_{\text {measured }}$. $\mathrm{GF}_{\text {bias }}$ should be less than $\sim 3 \%$ for a well calibrated HTDMA. This corresponds to \pm 0.05 uncertainty of ammonium sulphate GF at $90 \% \mathrm{RH}$.

HTDMA1 is not at all affected by the temperature drop because all relevant parts are in a temperature controlled housing, and hence the RH remains constant and the measured GFs accurate. HTDMA2 is not insulated and the temperature of its second DMA dropped by $6^{\circ} \mathrm{C}$ roughly following the room temperature (not shown). Nevertheless the RH remained constant owing to the short response time of the humidification system and all measured GFs were accurate. HTDMA4, 5, and 6 were not able to keep the RH constant. The temperature of DMA2 is held constant in HTDMA4 and 6 , while a considerable part of the sheath flow loop of DMA2 is exposed to ambient temperature. A drop or increase of laboratory temperature leads to a lower or higher RH in the external parts of the sheath flow loop, respectively, and all water absorbing parts such as filters then act as a source or sink of water vapour. This effect drives the RH in DMA2 off its target value, unless the counteracting regulation capacity of the humidification system is strong enough. Distinctly lower laboratory temperatures compared to DMA2 can also lead to condensation in the external parts of the sheath flow loop, in which case an effective RH control is impossible. Similar effects are responsible for the RH drift of HTDMA5, in which the humidifier is held at constant temperature but not DMA2. These two effects are the cause of the RH drop seen in Fig. 4 at time zero. The $\mathrm{GF}_{\text {bias }}$ values in Fig. 4 show that the sharp temperature drop also causes large systematic measurement errors of up to 50\% in HTDMA5 and 6, i.e. the particles where sometimes not deliquesced despite a measured RH clearly above $80 \%$. HTDMA6 showed up to 3 growth modes indicating rapid $\mathrm{RH}$ fluctuations or strong inhomogeneity within the flow. HTDMA3 was running a humidogram during the temperature drop and therefore no conclusion can be drawn for its ability to keep a constant RH within varying laboratory temperature. However, even at a 


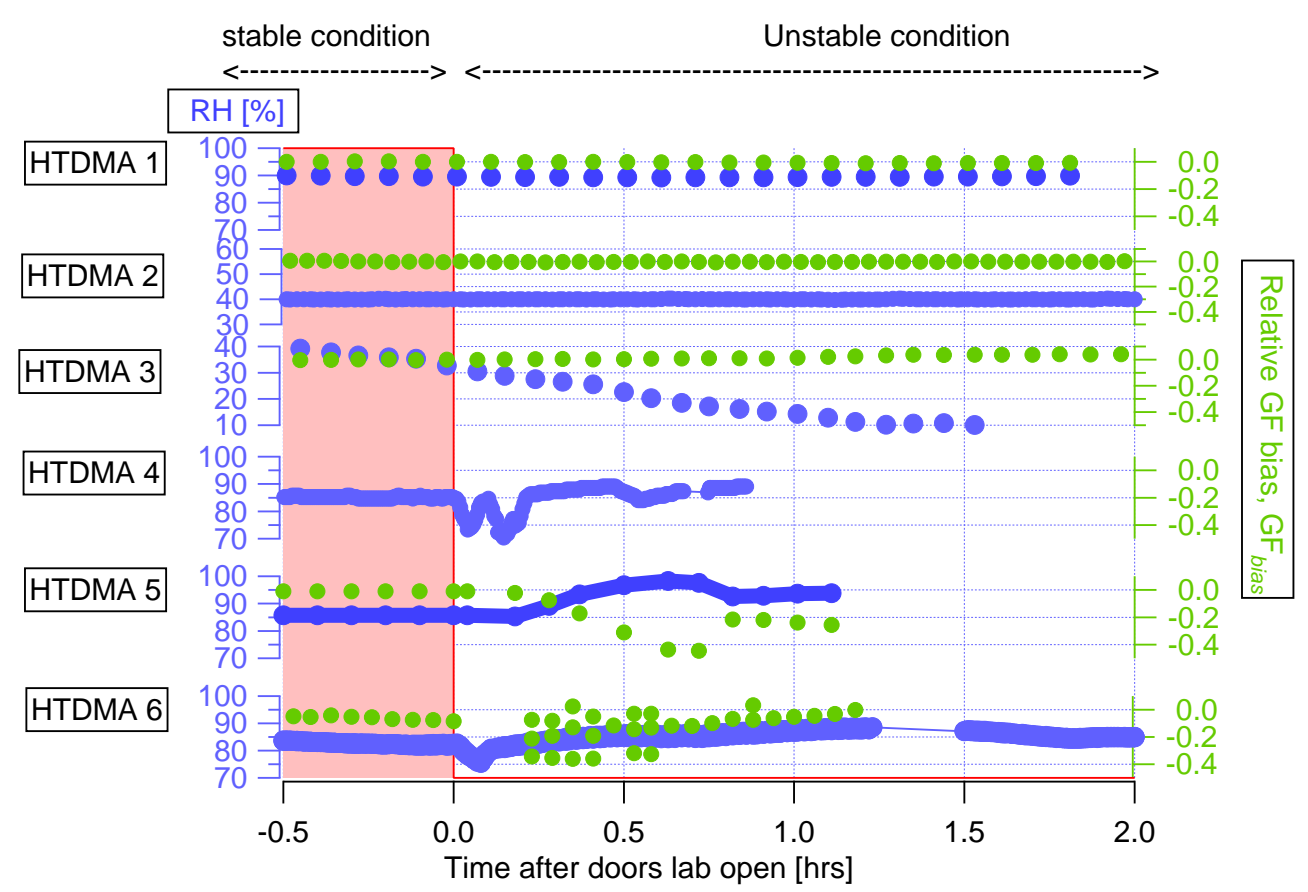

Fig. 4. Testing the influence of a laboratory temperature drop from $24^{\circ} \mathrm{C}$ to $14^{\circ} \mathrm{C}$ on the RH stability and measurement accuracy. The blue dots (left axis) show the RH inside DMA2. The relative deviation of the measured GF from the theoretical value (calculated from Topping et

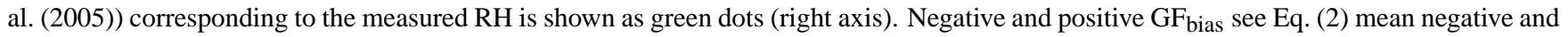
positive deviations from theory, respectively. HTDMA4 was not measuring GFs during this test and HTDMA3 was running a humidogram.

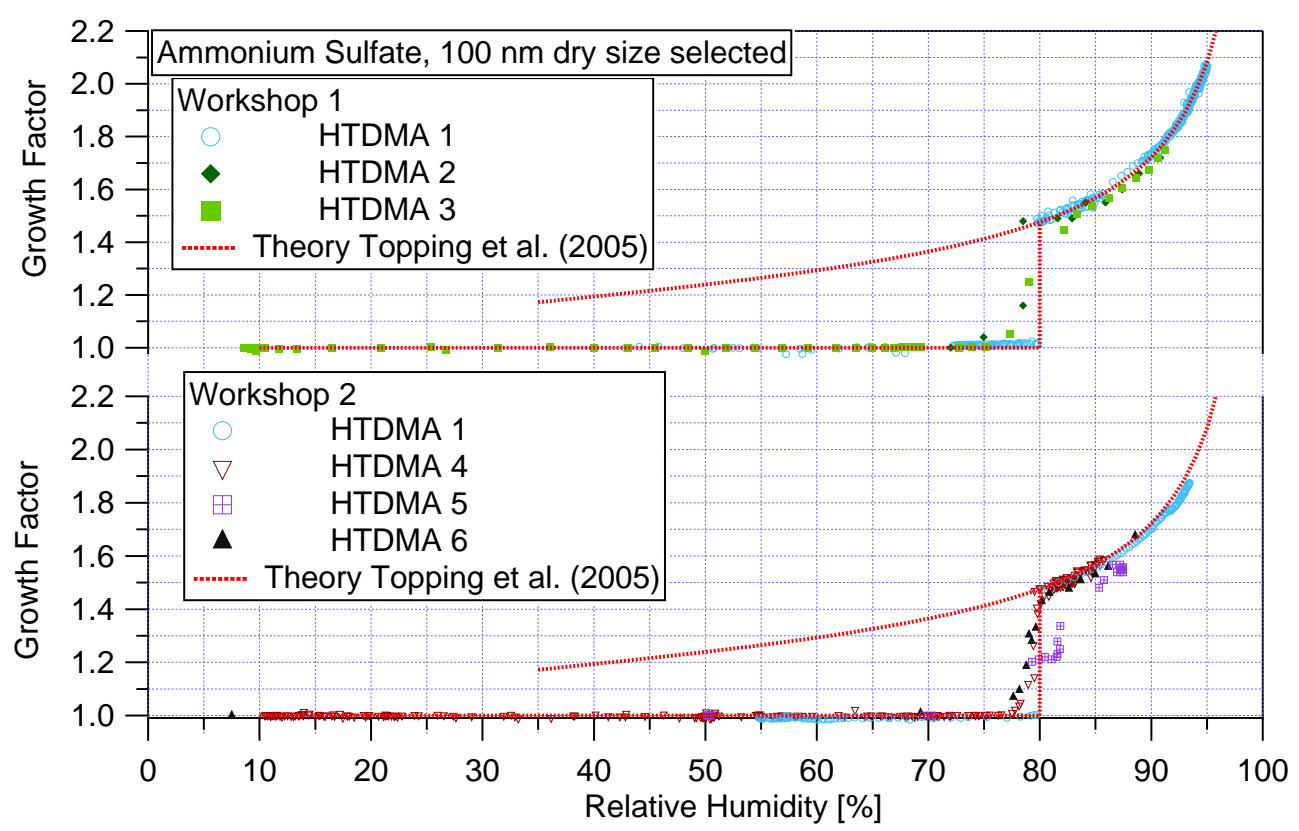

Fig. 5. Humidograms of ammonium sulphate measured with the six HTDMAs. Data points describe GF measured by the six HTDMAs, dashed lines represent theoretical GF (Topping et al., 2005). For HTDMA1, 3 and 4, due to their humidification systems (see Sect. 2.2.3), only measurements performed during decreasing or stable RH are shown. During increasing RH the aerosol could already deliquesce prior to entering DMA2. 
Table 2. Measured deliquescence RH and GF (at 85 and 90\% RH) of ammonium sulphate.

\begin{tabular}{|c|c|c|c|c|c|c|c|}
\hline & HTDMA1 & HTDMA2 & HTDMA3 & HTDMA4 & HTDMA5 & HTDMA6 & Reference values \\
\hline Deliquescence RH [\%] & $80.2 \pm 0.3$ & $78.5 \pm 3$ & $79.5 \pm 3$ & $79.2 \pm 1.4$ & $81 \pm 2$ & $79.0 \pm 1.2$ & $79.9^{1)}$ \\
\hline Number of measurements & 7 & 1 & 3 & 12 & 8 & 7 & \\
\hline $\mathrm{GF}$ at $85 \pm 0.5 \% \mathrm{RH}$ & $1.56 \pm 0.03$ & $1.55 \pm 0.03$ & $1.54 \pm 0.03$ & $1.57 \pm 0.01$ & $1.48 \pm 0.04$ & $1.53 \pm 0.04$ & $1.567^{2)}$ \\
\hline Number of measurements & 14 & 2 & 1 & 6 & 11 & 9 & \\
\hline Deviation to the theory [\%] & -0.3 & -1.1 & -1.8 & 0.2 & -5.6 & -2.1 & \\
\hline GF at $90 \% \mathrm{RH}$ & $1.72 \pm 0.03$ & $1.69 \pm 0.03$ & $1.67 \pm 0.03$ & No data & No data & No data & $1.722^{2)}$ \\
\hline Number of measurements & 8 & 2 & 1 & 0 & 0 & 0 & \\
\hline Deviation to the theory [\%] & -0.12 & -1.9 & -3 & & & & \\
\hline
\end{tabular}

1) The measured DRH of ammonium sulphate is $79.9 \% \mathrm{RH}$ for large aerosol particles

(Tang and Munkelwitz, 1993).

2) The theoretical GF (for $D_{0}=100 \mathrm{~nm}$ ) are taken from Topping et al. (2005).

low $\mathrm{RH}(10 \%)$ an increase of $\mathrm{GF}_{\text {bias }}$ was observed (from 0 to $5 \%$ ) during the first 2 hours of the temperature drop. A consequence of the occurrence of $\mathrm{GF}_{\text {bias }}$ larger than a few percent is that all measurements conducted under conditions with varying laboratory temperature exceeding a critical gradient must be treated as invalid.

Concluding, it is best to have the whole HTDMA system including sheath air loops in temperature controlled boxes/baths. A reduction of the water absorption capacity in the external parts of the sheath flow loop helps increasing the robustness of the $\mathrm{RH}$ control for those systems that are not completely temperature controlled.

\subsubsection{Humidograms of pure ammonium sulphate}

Pure ammonium sulphate was chosen as a test substance because it is a major component of the atmospheric aerosol and its thermodynamic behaviour is well characterised. In addition, ammonium sulphate particles are not volatile and exhibit an approximately spherical structure which renders a shape correction unnecessary. Theoretical diameter growth factors were obtained from the Aerosol Diameter Dependent Equilibrium Model (ADDEM; Topping et al., 2005). Measurements of ammonium sulphate particles with dry diameter $D_{0}=100 \mathrm{~nm}$ were performed at the beginning of the intercomparison period and at regular intervals thereafter. This included complete growth curves as shown in Fig. 5, wherein only data points with an $\mathrm{RH}$ gradient $\mathrm{RH}<1 \%$ during a scan were considered.

Both hydration and dehydration curves of ammonium sulphate were recorded in this study, lasting between $40 \mathrm{~min}$ to $10 \mathrm{~h}$ for a complete RH cycle depending on the instrument (see Table 1). The duration of an $\mathrm{RH}$ ramp is limited by the response time to $\mathrm{RH}$ set point changes in some instruments. HTDMA2, 3, 5 and 6 have very short response times, though a certain RH gradient should not be exceeded in order to assure equilibration of the RH in DMA2 and to keep RH changes during the scan of a single growth spectrum low. In addition to that, some instruments provided automated $\mathrm{RH}$ ramping and therefore better $\mathrm{RH}$ resolution in the hydration curve, desirable for a precise characterisation of the deliquescence transition (see Table 1).

The measurements of the six HTDMAs were reproducible and the GFs at $85 \% \mathrm{RH}$ agreed with theory within $\pm 2.1 \%$ for all HTDMAs except HTDMA5 which exhibited errors of up to $\pm 5.6 \%$ (see also Table 2 for a summary of the validation results). It is interesting to note that at the deliquescence transition all HTDMAs, except HTDMA1, measured GFs in between the solid crystal (1.00) and the completely dissolved solution droplet (1.48). As this phase transition is expected to be very fast, on the order of a few milliseconds for sub-micron ammonium sulphate particles, all points should lay either on the upper or lower branch of the growth curve (Biskos et al., 2006). Impurities in the aerosol can be excluded because no such intermediate GFs were measured by HTDMA1, which sampled from the same nebuliser. It has to be emphasized that none of these "intermediate" points are the result of averaging two separated growth modes from solid and hydrated particles. Bimodal growth distributions can occur when the RH in DMA2 crosses the DRH during a scan. Two phenomena could explain the measurement of intermediate GFs. First, aerosol and sheath air RH are not the same and they equilibrate within the DMA2 or second, the sheath air in DMA2 experiences a temperature gradient while passing through it, which results in a $\mathrm{RH}$ gradient. In both cases, the aerosol will deliquesce during passage through DMA2, thus resulting in an apparent size of the aerosol particle in between the solid and deliquesced state. Biskos et al. (2006) showed that such intermediate points are measured at $\mathrm{RH}$ close to the $\mathrm{DRH}$ when the $\mathrm{RH}$ difference between aerosol and sheath air flow is larger than $3 \% \mathrm{RH}$, which is the most probable explanation for the intermediate GFs measured by HTDMA5 and potentially also for HTDMA6 with two independent humidification systems. In HTDMA2 it is ensured that both aerosol and sheath air have the same RH and there this artefact is most probably caused by temperature gradients in the DMA2 which lacks a good temperature control. The heat exchangers for the sheath flow might be insufficient in HTDMA4 where DMA2 is submersed in a water bath. Additionally, particular care is needed for HTDMA4 to 


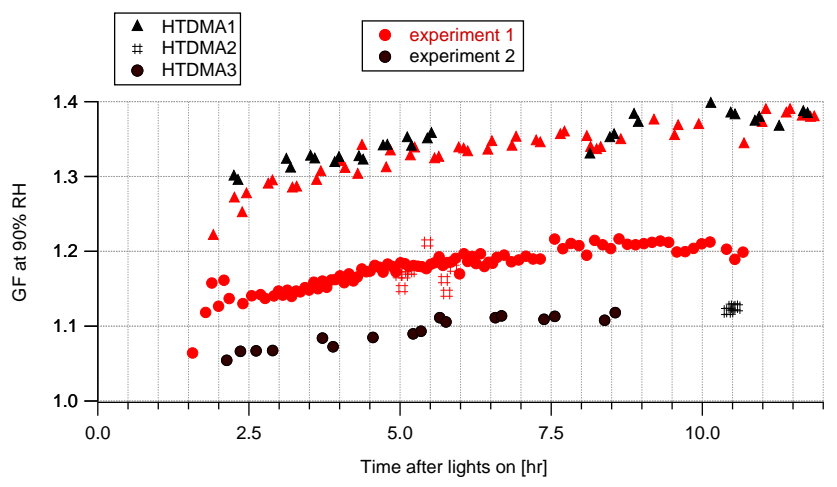

Fig. 6. GF of SOA at $90 \%$ RH during the first workshop for two experiments.

avoid large differences between the RH in the aerosol sample and the one in the sheath air. The existence of temperature gradients within the sheath air of DMA2 leads to inaccurate measurements of the DRH as shown in Table 2.

Summarising, all HTDMAs (except HTDMA5) find a good agreement between measured and theoretically predicted growth factors (difference $<2.1 \%$ ). The DRH point is also measured within $\Delta \mathrm{RH}< \pm 3 \%$ uncertainty of the literature value $\mathrm{DRH}=79.9 \%$, indicating a fairly accurate $\mathrm{RH}$ calibration. The higher deviation of HTDMA5 is explained with the large differences between the RH in the aerosol sample $(50 \%)$ and the one in the sheath air $(85 \%)$.

\subsection{Intercomparison with SOA}

The hygroscopic growth behaviour of SOA has been investigated in several previous studies. Some of these studies appear to agree with each other, some do not. However, a direct comparison of such results is rarely possible because the hygroscopic properties of SOA particles depend on precursor concentration, photochemical reaction time, etc. (Duplissy et al., 2008) and because the measurements were done at different RH in different studies. The performance of HTDMAs for SOA can therefore be best assessed by simultaneous measurements. SOA generated at the same conditions should have the same properties.

SOA produced by photo-oxidation of $\alpha$-pinene was investigated during the two workshops. HTDMA1, the only instrument participating at both workshops, measured slightly different GFs (Figs. 6 and 7). The SOA properties from the third experiment are not representative because a new smogchamber bag was used, which had not yet undergone the standard cleaning procedures. However, this does not compromise the suitability of the generated SOA for comparing the performance of different HTDMA instruments.

The general sampling strategy employed was to measure just one dry size for several hours and then switch to a larger dry size. The upper and lower limit of possible dry size at a certain time are imposed by low particles concentrations and biases due to the influence of multiply charged particles, respectively. Both size limits increase with time as the mean diameter of the size distribution increases. Always starting off with the largest possibly dry size made it possible to measure at a constant dry size for a longer time before changing to a larger dry size. This strategy was chosen to measure possible temporal trends of hygroscopic growth due to photochemical aging, while it is not suitable to determine whether or not the hygroscopic growth at a certain time is size dependent. It should also be noted that below $100 \mathrm{~nm}$ the Kelvin effect becomes increasingly important i.e. aerosol particles of identical composition will take up less water if they are smaller. All HTDMAs measured an increase of the GF with photo-chemical reaction time for a given dry size. It is not clear how the hygroscopicity of aerosol particles of different dry sizes compares. As the aerosol particles of a given size in the chamber are created by a combination of homogeneous nucleation, condensation and coagulation it is difficult to predict a general trend in the hygroscopicity of aerosol particles with different size at a given time. In contrast to the good agreement between the HTDMAs found for the inorganic salts, significant differences between the HTDMAs were observed for SOA. Possible reasons for part of the discrepancies will be discussed in the following.

HTDMA1 measured during all the $\alpha$-pinene experiments, and measured similar growth factors during experiments 1 and 2 (Fig. 6), while HTDMA2 and 3 measured different growth factors in the different experiments. HTDMA2 and HTDMA3 measured growth factors in reasonable agreement with each other, but lower than HTDMA1, although only a limited amount of data was collected by HTDMA2. These experiments revealed significant discrepancies between the HTDMA measurements for SOA, whereas they agreed well for inorganic salts. This implies that the SOA has a particular property, which makes it much more difficult to obtain accurate growth factor measurements using a HTDMA. Based on the tests performed during these experiments no instrument design feature could be identified as an obvious reason for these discrepancies. Hypotheses for possible causes are discussed in Sect. 4.3.

Results from the second workshop are presented in Fig. 7. The upper panel shows results as analysed by each group with their own analysis procedures, while the lower panel shows the same data, re-analysed and corrected according to the recommendations provided in this paper (see Sect. 5).

The GF values for HTDMA4 in the top panel of Fig. 7 are too low because the RH in DMA1 was too high during this particular experiment (approx. 33\% instead of $<15 \%$ as during all other experiments). SOA experiences a GF of $\sim 1.025$ at $\mathrm{RH}=33 \%$ (measured with HTDMA1, while performing a humidogram; Duplissy et al., 2008) and therefore the GF at $90 \%$ is underestimated by $2.5 \%$. This bias was corrected in the data shown in the bottom panel of Fig. 7. The effects of a too high RH in DMA1 would not be detected with validation experiments using e.g. pure $\left(\mathrm{NH}_{4}\right)_{2} \mathrm{SO}_{4}$, as they remain 


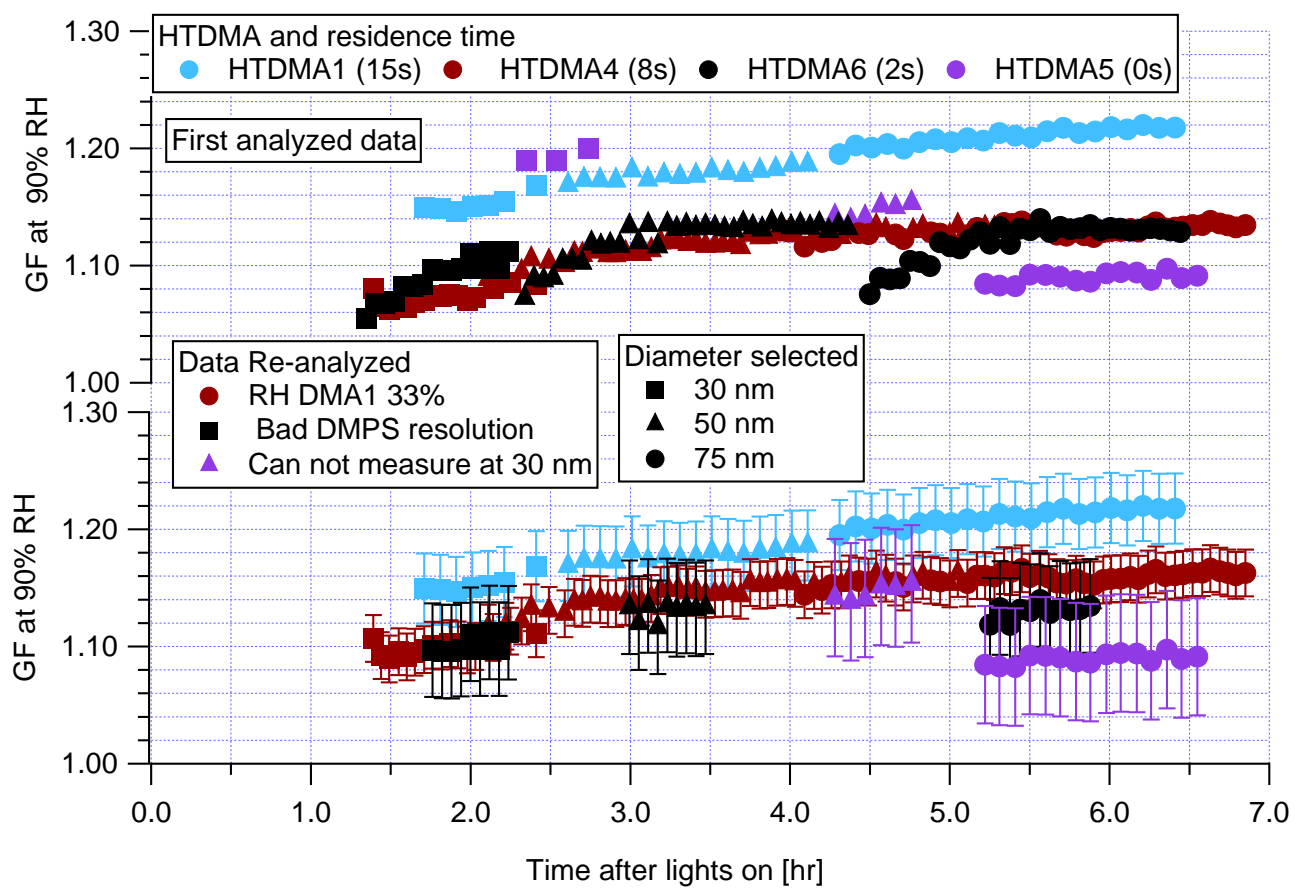

Fig. 7. GF of SOA (at $90 \% \mathrm{RH}$ ) during the second workshop. The top panel shows the results as provided by the respective HTDMA operators using their own analysis procedures. The bottom panel shows the results after a reanalysis using the procedure recommended in this paper.

crystalline at $\mathrm{RH}<80 \%$. As a consequence the $\mathrm{RH}$ in DMA1 has to be monitored continuously in order to ensure dry conditions at all times. A RH of less than $15 \%$ in DMA1 is recommended as a trade-off between minimizing the amount of residual water during dry size selection and keeping the technical effort reasonably low.

HTDMA6 investigated three different dry diameters during the course of the experiment ( $D_{0}=30,50$ and $\left.75 \mathrm{~nm}\right)$. Uncorrected results from this instrument show an initial fast increase in GF followed by a plateau. A change of $D_{0}$ results in an abrupt GF change. This artefact is caused by a too coarse growth factor resolution of the employed DMPS software, resulting in a high GF uncertainty. All points with insufficient sizing resolution were removed during the reanalysis (bottom panel of Fig. 7).

HTDMA5 also changed the selected dry diameter during the course of the experiment $\left(D_{0}=50\right.$ and $\left.75 \mathrm{~nm}\right)$ and shows lower GF when larger aerosol particles are selected. A possible explanation for this discrepancy is an insufficient equilibration time. As shown in Fig. 1, HTDMA5 only prehumidifies the aerosol at $50 \%$ RH ( $8 \mathrm{~s})$ before being fully humidified to the target $\mathrm{RH}$ within the DMA2, thus providing no residence time at all at high $\mathrm{RH}$ prior to sizing inside the 2nd DMA. The measured growth factors are low because the SOA particles are not fully in equilibrium with the high $\mathrm{RH}$ during their presence in DMA2. Again, an insufficient residence time at high $\mathrm{RH}$ prior to sizing in DMA2 can influence the measured hygroscopic growth (Chan and Chan, 2005; Sjogren et al., 2007). Results shown for HTDMA5 in Fig. 7 indicate that larger aerosol particles are more affected by this effect. It is therefore suggested to expose the aerosol sample to the nominal $\mathrm{RH}$ during at least $10 \mathrm{~s}$ before measuring the GF. Analogously, it is also suggested to allow the aerosol particle to dry for at least $10 \mathrm{~s}$ before the selection of the dry size by the DMA1.

After careful reanalysis of all raw data, good agreement between the GFs measured by the different HTDMAs was found within the first $4 \mathrm{~h}$ of the experiment when $D_{0} \leq 50 \mathrm{~nm}$. However, discrepancies remained for aerosol particles with $D_{0}=75 \mathrm{~nm}$ selected after $6 \mathrm{~h}$ of photochemical reaction. HTDMA5, 6, 4 and 1 measured GF values of 1.09, 1.13, 1.15 and 1.2 respectively with a residence time of $0,2,8$ and $15 \mathrm{~s}$, respectively. This trend is in line with the hypothesis of kinetic limitations, though these discrepancies could be also due to temperature. The HTDMAs operate at different temperature, which could lead to a different partitioning of the SOA. At higher temperature, the more volatile compounds can evaporate from the aerosol particle phase to the gas phase. The remaining aerosol particle will have therefore a different chemical composition and thus could have different hygroscopic properties (Asa-Awuku et al., 2009; Meyer et al., 2009). 


\subsection{Discussion of discrepancies found for SOA}

The order of magnitude of the hygroscopic growth of SOA derived from photo-oxidation of $\alpha$-pinene is well known, even though discrepancies between measurements made by different HTDMAs remain an open issue, which could not be resolved during the limited number of direct intercomparison experiments conducted so far. A first hypothesis for the cause of these complex discrepancies is that the HTDMAs affect the gas-particle equilibrium of semi-volatile compounds of the SOA in a different manner by the way they dry or wet the aerosol. A second hypothesis is that the temperature at which the hygroscopicity is measured has an influence on the partitioning between gas and aerosol phase components, again leading to changes in the observed GF. A third hypothesis is that the residence time of the aerosol inside the instrument also could play a role, due to e.g. slow reversibility of oligomer formation, which could result in a slow increase of the equilibrium GF with increasing time at high $\mathrm{RH}$.

\section{Recommendations for operating HTDMAs}

In the following we provide recommendations for design and construction of HTDMA instruments as well as for standardised calibration, operation, quality assurance and data analysis procedures, based on the results of these workshops. Several key points which are commonly acknowledged by experienced HTDMA users are also included for completeness.

\subsection{HTDMA design}

- The sample RH should be drier than $15 \%$ RH during at least $10 \mathrm{~s}$ prior to entering DMA1. The sample RH at the entrance of the first DMA and in the excess air should be monitored (see Sect. 4.2).

- The humidified sample should be equilibrated to the nominal RH during at least $10 \mathrm{~s}$ before entering DMA2. Residence times longer than $\sim 40 \mathrm{~s}$ are not recommended due to potential evaporation artefacts of semivolatile material such as ammonium nitrate. The exact residence time should be measured and reported (see Sect. 2.2.4).

- Temperature gradients in DMA2 should be minimized. This can be achieved with a well-stirred water bath or an insulated and temperature controlled box. Care has to be taken to have sufficiently large heat exchangers of the sheath air flow (see Sect. 4.1.3).

- The HTDMA should be able to hold the RH constant at the nominal value $( \pm 2 \% \mathrm{RH})$ over an extended period of time (days). This can be done using PID feedback loops (see Sect. 4.1.2).
- All sections containing high RH flow should be temperature controlled to avoid water vapour condensation and to improve the performance under conditions with variable room temperature. Alternatively the RH buffering capacity of the high RH sections should be reduced as far as possible. If instability of the RH occurs due to change of ambient temperature, then the data should not be used (see Sect. 4.1.3).

- The temperature should be measured in the sheath and excess air of DMA2, as closely to the DMA2 as possible, and the temperature difference should be $\leq 0.1^{\circ} \mathrm{C}$, in order to check that no $\mathrm{RH}$ gradient greater than $\sim 0.7 \%$ exists in the DMA2 at $\mathrm{RH}<90 \%$ (see Sect. 2.2.2).

- The RH ramping should be automated for improved measurements of hydration/dehydration curves. The $\mathrm{RH}$ changes should result in a RH gradient larger $2 \%$ RH downstream of the humidifier (see Sect. 4.1.4).

\subsection{Instrument calibration (see Sect. 3.1)}

- The analogue output for controlling the HV supply as well as the HV amplification factor must be calibrated.

- All flows rates must be calibrated.

- Temperature and dew point measurement must be calibrated.

- Capacitive RH sensors must be calibrated.

\subsection{Instrument validation (see Sects. 4.1 and 3.2)}

- Certified PSL spheres should be used to verify the sizing of the DMA.

- The validation of accurate sizing and RH measurement should be done by recording a full hydration curve of ammonium sulphate including the deliquescence transition.

- The correct size dependence of the GF of ammonium sulphate across the range of selected dry diameters should at least be verified for the nominal RH of the field measurements.

\subsection{Instrument operation}

- Small sizing offsets between DMA1 and DMA2 must be determined for all dry sizes with regular dry scans. We suggest doing this on a weekly basis.

- The measurement quality can be improved by constraining the scanned diameter range to a physically reasonable growth factor range. 
- We suggest conducting ambient measurements at $\mathrm{RH}=90 \%$ (where most ambient salts are deliquesced) and at a selection of the following aerosol particle dry diameters: 35, 50, 75, 110, 165 and/or $265 \mathrm{~nm}$. This aims at providing comparable data sets from different sites.

\subsection{Recommendation for data analysis}

- An SMPS (or an alternative instrument giving the size distribution of the measured aerosol) must run beside the HTDMA and all measurements with a contribution of less than $80 \%$ singly charged aerosol particles must be removed (see Sect. 3.4).

- Small sizing offsets between DMA1 and DMA2 must be accounted for in the data analysis (see Sect. 3.3).

- An appropriate TDMA inversion algorithm such as TDMAinv or TDMAfit must be applied (see Sect. 3.3).

- All measured GFs should be recalculated to the nominal RH if the measured $\mathrm{RH}$ was within $\pm 2 \%$ of the target RH. All data outside the RH tolerance should be ignored (see Sect. 3.3).

Acknowledgements. This work was performed in the framework of the Research Infrastructure Action under the FP6 "Structuring the European Research Area" Programme, EUSAAR Contract No. RII3-CT-2006-026140. It was further supported by the EC projects EUCAARI and ACCENT, the ESF programme INTROP as well as the Swiss National Science Foundation. Partner 4 acknowledges financial support from the French National Research Agency (ANR) under the AEROTROP programme and the PRIMEQUAL programme.

Edited by: A. Wiedensohler

\section{References}

Asa-Awuku, A., Engelhart, G. J., Lee, B. H., Pandis, S. N., and Nenes, A.: Relating CCN activity, volatility, and droplet growth kinetics of $\beta$-caryophyllene secondary organic aerosol, Atmos. Chem. Phys., 9, 795-812, 2009,

http://www.atmos-chem-phys.net/9/795/2009/.

Biskos, G., Paulsen, D., Russell, L. M., Buseck, P. R., and Martin, S. T.: Prompt deliquescence and efflorescence of aerosol nanoparticles, Atmos. Chem. Phys., 6, 4633-4642, 2006, http://www.atmos-chem-phys.net/6/4633/2006/.

Brechtel, F. J. and Kreidenweis, S. M.: Predicting particle critical supersaturation from hygroscopic growth measurements in the humidified TDMA. Part II: Laboratory and ambient studies, J. Atmos. Sci., 57, 1872-1887, 2000.

Chan, M. N. and Chan, C. K.: Mass transfer effects in hygroscopic measurements of aerosol particles, Atmos. Chem. Phys., 5, 2703-2712, 2005, http://www.atmos-chemphys.net/5/2703/2005/.
Chuang, P. Y.: Measurement of the timescale of hygroscopic growth for atmospheric aerosols, J. Geophys. Res., 108, 4282, doi:10.1029/2002JD002757, 2003.

Cocker III, D. R., Whitlock, N. E., Flagan, R. C., and Seinfeld, J. H.: Hygroscopic properties of Pasadena, California aerosol, Aerosol Sci. Technol., 35, 637-647, 2001.

Colberg, C. A., Luo, B. P., Wernli, H., Koop, T., and Peter, T.: A novel model to predict the physical state of atmospheric $\mathrm{H}_{2} \mathrm{SO}_{4} / \mathrm{NH}_{3} / \mathrm{H}_{2} \mathrm{O}$ aerosol particles, Atmos. Chem. Phys., 3, 909-924, 2003, http://www.atmos-chem-phys.net/3/909/2003/.

Cruz, C. N. and Pandis, S. N.: Deliquescence and hygroscopic growth of mixed inorganic-organic atmospheric aerosol, Environ. Sci. Technol., 34, 4313-4319, 2000.

Cubison, M. J., Coe, H., and Gysel, M.: A modified hygroscopic tandem DMA and a data retrieval method based on optimal estimation, J. Aerosol Sci., 36, 846-865, 2005.

Duplissy, J., Gysel, M., Alfarra, M. R., Dommen, J., Metzger, A., Prevot, A. S. H., Weingartner, E., Laaksonen, A., Raatikainen, T., Good, N., Turner, F., McFiggans, G., and Baltensperger, U.: Cloud forming potential of secondary organic aerosol under near atmospheric conditions, Geophys. Res. Lett., 35, L03818, doi:10.1029/2007GL031075, 2008.

Fletcher, C. A., Johnson, G. R., Ristovski, Z. D., and Harvey, M.: Hygroscopic and volatile properties of marine aerosol observed at Cape Grim during the P2P campaign, Env. Chem., 4, 162-171, 2007.

Gysel, M., Weingartner, E., and Baltensperger, U.: Hygroscopicity of aerosol particles at low temperatures. 2. Theoretical and experimental hygroscopic properties of laboratory generated aerosols, Environ. Sci. Technol., 36, 63-68, 2002.

Gysel, M., Crosier, J., Topping, D. O., Whitehead, J. D., Bower, K. N., Cubison, M. J., Williams, P. I., Flynn, M. J., McFiggans, G. B., and Coe, H.: Closure study between chemical composition and hygroscopic growth of aerosol particles during TORCH2, Atmos. Chem. Phys., 7, 6131-6144, 2007, http://www.atmos-chem-phys.net/7/6131/2007/.

Gysel, M., McFiggans, G. B., and Coe, H.: Inversion of tandem differential mobility analyser (TDMA) measurements, J. Aerosol Sci., 40, 134-151, 2009.

Hallquist, M., Wenger, J. C., Baltensperger, U., Rudich, Y., Simpson, D., Claeys, M., Dommen, J., Donahue, N. M., George, C., Goldstein, A. H., Hamilton, J. F., Herrmann, H., Hoffmann, T., Iinuma, Y., Jang, M., Jenkin, M., Jimenez, J. L., KiendlerScharr, A., Maenhaut, W., McFiggans, G., Mentel, T. F., Monod, A., Prevot, A. S. H., Seinfeld, J. H., Surratt, J. D., Szmigielski, R., Wildt, J.: The formation, properties and impact of secondary organic aerosol: current and emerging issues, Atmos. Chem. Phys. Discuss., 9, 3555-3762, 2009,

http://www.atmos-chem-phys-discuss.net/9/3555/2009/.

Hennig, T., Massling, A., Brechtel, F. J., and Wiedensohler, A.: A tandem DMA for highly temperature-stabilized hygroscopic particle growth measurements between $90 \%$ and $98 \%$ relative humidity, J. Aerosol Sci., 36, 1210-1223, 2005.

Johnson, G. R., Ristovski, Z. D., D’Anna, B., and Morawska, L.: Hygroscopic behavior of partially volatilized coastal marine aerosols using the volatilization and humidification tandem differential mobility analyzer technique, J. Geophys. Res., 110, D20203, doi:10.1029/2004JD005657, 2005.

Johnson, G. R., Fletcher, C., Meyer, N. K., Modini, R., and Ris- 
tovski, Z.: A robust, portable H-TDMA for field use, J. Aerosol Sci., 39, 850-861, 2008.

Kerminen, V.-M.: The effects of particle chemical character and atmospheric processes on particle hygroscopic properties, J. Aerosol Sci., 28, 121-132, 1997.

Koehler, K. A., Kreidenweis, S. M., DeMott, P. J., Prenni A. J., Carrico, C. M., Ervens, B., and Feingold, G.: Water activity and activation diameters from hygroscopicity data - Part II: Application to organic species, Atmos. Chem. Phys., 6, 795-809, 2006, http://www.atmos-chem-phys.net/6/795/2006/.

Liu, B. Y. H., Pui, D. Y. H., Whitby, K. T., Kittelson, D. B., Kousaka, Y., and McKenzie, R. L.: Aerosol mobility chromatograph - new detector for sulfuric-acid aerosols, Atmos. Environ., 12, 99-104, 1978.

McMurry, P. H. and Stolzenburg, M. R.: On the sensitivity of particle size to relative humidity for Los Angeles aerosols, Atmos. Environ., 23, 497-507, 1989.

Meyer, N. K., Duplissy, J., Gysel, M., Metzger, A., Dommen, J., Weingartner, E., Alfarra, M. R., Fletcher, C., Good, N., McFiggans, G., Jonsson, Å. M., Hallquist, M., Baltensperger, U., and Ristovski, Z. D.: Analysis of the hygroscopic and volatile properties of ammonium sulphate seeded and un-seeded SOA particles, Atmos. Chem. Phys., 9, 721-732, 2009, http://www.atmos-chem-phys.net/9/721/2009/.

Mikhailov, E., Vlasenko, S., Niessner, R., and Pöschl, U.: Interaction of aerosol particles composed of protein and saltswith water vapor: hygroscopic growth and microstructural rearrangement, Atmos. Chem. Phys., 4, 323-350, 2004, http://www.atmos-chem-phys.net/4/323/2004/.

Paulsen, D., Dommen, J., Kalberer, M., Prevot, A. S. H., Richter, R., Sax, M., Steinbacher, M., Weingartner, E., and Baltensperger, U.: Secondary organic aerosol formation by irradiation of $1,3,5-$ trimethylbenzene- $\mathrm{NO}_{\mathrm{x}}-\mathrm{H}_{2} \mathrm{O}$ in a new reaction chamber for atmospheric chemistry and physics, Environ. Sci. Technol., 39, 2668-2678, 2005.

Paulsen, D., Weingartner, E., Alfarra, M. R., and Baltensperger, U.: Volatility measurements of photochemically and nebulizergenerated organic aerosol particles, J. Aerosol Sci., 37, 10251051, 2006.

Prenni, A. J., DeMott, P. J., Kreidenweis, S. M., Sherman, D. E., Russell, L. M., and Ming, Y.: The effects of low molecular weight dicarboxylic acids on cloud formation, J. Phys. Chem., A105, 11240-11248, 2001.

Prenni, A. J., Petters, M. D., Kreidenweis, S. M., DeMott, P. J., and Ziemann, P. J.: Cloud droplet activation of secondary organic aerosol, J. Geophys. Res., 112, D10223, doi:10.1029/2006JD007963, 2007.

Randall, D. A., Wood, R. A., Bony, S., Colman, R., Fichefet, T., Fyfe, J., Kattsov, V., Pitman, A., Shukla, J., Srinivasan, J., Stouffer, R. J., Sumi, A., and Taylor, K. E.: Climate Models and Their Evaluation, in: Climate Change 2007: The Physical Science Basis, Contribution of Working Group I to the Fourth Assessment Report of the Intergovernmental Panel on Climate Change, Cambridge University Press, Cambridge, UK and New York, NY, USA, 590-662, 2007.
Rood, M. J., Shaw, M. A., Larson, T. V., and Covert, D. S.: Ubiquitous nature of ambient metastable aerosol, Nature, 337, 537-539, doi:10.1038/337537a0, 1989.

Seinfeld, J. H. and Pandis, S. N.: Atmospheric chemistry and physics: From air pollution to climate change, John Wiley \& Sons, Inc., New York, USA, 2006.

Sjogren, S., Gysel, M., Weingartner, E., Baltensperger, U., Cubison, M. J., Coe, H., Zardini, A., Marcolli, C., Krieger, U. K., and Peter, T.: Hygroscopic growth and water uptake kinetics of twophase aerosol particles consisting of ammonium sulfate, adipic and humic acid mixtures, J. Aerosol Sci., 38, 157-171, 2007.

Stolzenburg, M. R. and McMurry, P. H.: TDMAFIT user's manual, University of Minnesota, Department of Mechanical Engineering, Particle Technology Laboratory, Minneapolis, USA, 1988.

Swietlicki, E., Hansson, H. C., Hameri, K., Svenningsson, B., Massling, A., McFiggans, G., McMurry, P. H., Petaja, T., Tunved, P., Gysel, M., Topping, D., Weingartner, E., Baltensperger, U., Rissler, J., Wiedensohler, A., and Kulmala, M.: Hygroscopic properties of submicrometer atmospheric aerosol particles measured with H-TDMA instruments in various environments - a review, Tellus, 60B, 432-469, 2008.

Tang, I. N. and Munkelwitz, H. R.: Composition and temperature dependence of the deliquescence properties of hygroscopic aerosols, Atmos. Environ., 27A, 467-473, 1993.

Topping, D. O., McFiggans, G. B., and Coe, H.: A curved multicomponent aerosol hygroscopicity model framework: Part 1 - Inorganic compounds, Atmos. Chem. Phys., 5, 1205-1222, 2005, http://www.atmos-chem-phys.net/5/1205/2005/.

Van Dingenen, R., Putaud, J.-P., Martins-Dos Santos, S., and Raes, F.: Physical aerosol properties and their relation to air mass origin at Monte Cimone (Italy) during the first MINATROC campaign, Atmos. Chem. Phys., 5, 2203-2226, 2005, http://www.atmos-chem-phys.net/5/2203/2005/.

Villani, P., Picard, D., Michaud, V., Laj, P., and Wiedensohler, A.: Design and validation of a volatility hygroscoipic tandem differential mobility analyser (VHTDMA) to characterize the relationships between the thermal and hygroscopic properties of atmospheric aerosol particles, Aerosol Sci. Technol., 42, 729-741, 2008.

Virkkula, A., Van Dingenen, R., Raes, F., and Hjorth, J.: Hygroscopic properties of aerosol formed by oxidation of limonene, $\alpha$ pinene, and $\beta$-pinene, J. Geophys. Res., 104, 3569-3579, 1999.

Wang, J., Jacob, D., J., and Martin, S., T.: Sensitivity of sulfate direct climate forcing to the hysteresis of particle phase transitions, J. Geophys. Res., 113, D11207, doi:10.1029/2007JD009368, 2008.

Weingartner, E., Gysel, M., and Baltensperger, U.: Hygroscopicity of aerosol particles at low temperatures. 1. New low-temperature H-TDMA instrument: Setup and first applications, Environ. Sci. Technol., 36, 55-62, 2002. 